\title{
The Design and Implementation of Smart Campus System
}

\author{
Tianping Bi, Xuemei Yang*, Meili Ren \\ School of Management, Shenyang Jianzhu University, Shenyang, China. \\ * Corresponding author. Tel: +86-18940037634; email: 1123947546@qq.com \\ Manuscript submitted March 13, 2016; accepted July 13, 2016. \\ doi: $10.17706 /$ jcp.12.6.527-533
}

\begin{abstract}
To improve the educational environment and the comprehensive management level of the universities, the smart campus system has been constructed based on BIM (Building Information Modeling) and 3DGIS (Geographic Information System) platform in this study. Using Autodesk Revit software to build model relied on BIM technology and Skyline software to design the spatial database relied on 3DGIS technology. A 3D visualization campus information system called smart campus was constructed, which provides feasible solutions for constructing smart campus.
\end{abstract}

Key words: Smart campus, BIM, 3DGIS, Skyline, Revit.

\section{Introduction}

Smart campus is the product of the rapid development of the GIS technology, computer network technology and internet of things technology [1]-[4]. It has three core characteristics: personalized services, information services, environment platforms [5], [6]. The ideas of constructing smart campus were based on Internet of Things and utilized advanced information technology to implement the application system, which was based on the digital environment. It draws support from the integration and combination of application services to realize the campus information acquisition, sharing and services, so as to promote the intelligence process of teaching, scientific research and services [7].

With the development of higher education in China, the infrastructure construction and integrated management of the campus are faced with unprecedented challenges [8]. For example, infrastructures are facing construction problems and expansions. However, the basic data of school infrastructures exists many problems such as long time span, lack of scientific management and so on. All these problems for school infrastructure construction and maintenance have brought many difficulties. Therefore, a more effective, intuitive, and comprehensive modern management technology is needed to improve the school management level [9]. The smart campus construction can meet the requirement of information management in colleges and universities. Based on Shenyang Jianzhu University smart campus project, here we introduced how to implements the smart campus construction.

\section{Overall System Design Ideas}

The evolution of smart campus construction is a long-term process, needing to follow the principle of unified planning, implemented step by step and gradually improved [10]. According to the overall development strategy of school, the smart campus overall design will use the basic strategy which is of new application service system, perfect the available application system and integrate the original system. Overall construction work is divided into three stages: firstly, construct the smart campus' support platform; 
secondly expand the core application system; finally, deepen the comprehensive information service system.

Smart campus construction is a long-term process. It needs unified planning. According to the school's overall development strategy, the general design of smart campus will use the basic strategy of new application service system to improve the available application system and integration of the original application system simultaneously [11], [12]. The whole construction work is divided into three stages: the first stage is supporting platform for smart campus infrastructure; the second stage is the expansion phase of the wisdom of the campus core application system; the third stage is a stage of deepening in collaborative applications, decision support and comprehensive information service system. Fig. 1 shows the functional modules of the smart campus platform.

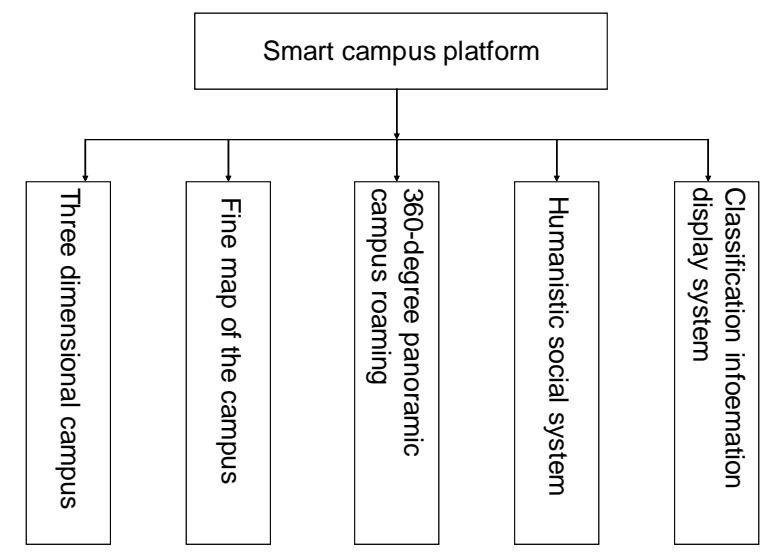

Fig. 1. Intelligent campus function module structure.

\section{Construction Content}

1) Building management. Building management function is the core module in the smart campus system. The module is mainly provided for establishing the Revit building model. It can display the internal structure, rooms, room size, use function etc.

2) Query capability. The module mainly includes the following five functions: location query, visibility analysis, basic measuring function, establishing the geographical position of each building coordinate information and measuring the distance between the set point.

3) Display panoramic campus. Smart campus provides a three-dimensional visual interface, campus flight browsing, releasing information on facility maintenance and road construction.

4) Information management. Information management system for the administrator is used to update the data timely and release the latest campus information.

\section{System Design}

\subsection{The Introduction of Software Technology}

\subsubsection{BIM technology}

Building Information Modeling (BIM) is rich in architectural space, which can be used to implement the project of digital management and has a large number of applications in various engineering fields [13]. But the BIM model lacking of space data and the visual expression of image is not specific enough, which was mainly used in single project engineering design and management of the application in the past, but now in the engineering design and management a single project.

\subsubsection{DGIS technology}

3D Geographic Information System (3DGIS) is based on spatial database technology, from micro to macro 
engaged in oriented mass of 3D geospatial data storage, management and visualization analysis applications and supporting a wide range of spatial data sets, which can be used to support collaborative analysis of large-scale engineering and sharing applications [14]. However, 3DGIS has the disadvantage of building solid model with fine expression.

Therefore, the combination of BIM technology and 3DGIS technology is an indispensable component of the construction of campus refinement and rapid visualization [15]. A combination of both at the present stage has important research value and practical significance.

\subsection{Technical Route}

The design of smart campus was that using the fusion of BIM technology and GIS technology to present the buildings information on the GIS software and realize a series of functions. During the design process, Fig. 2 shows the technology roadmap. Firstly, we established precise model in Revit to receive the information. Secondly, using $3 \mathrm{ds}$ Max software to process the model. Finally, it could realize the buildings information expressed in GIS software.

\subsection{Spatial Database Design}

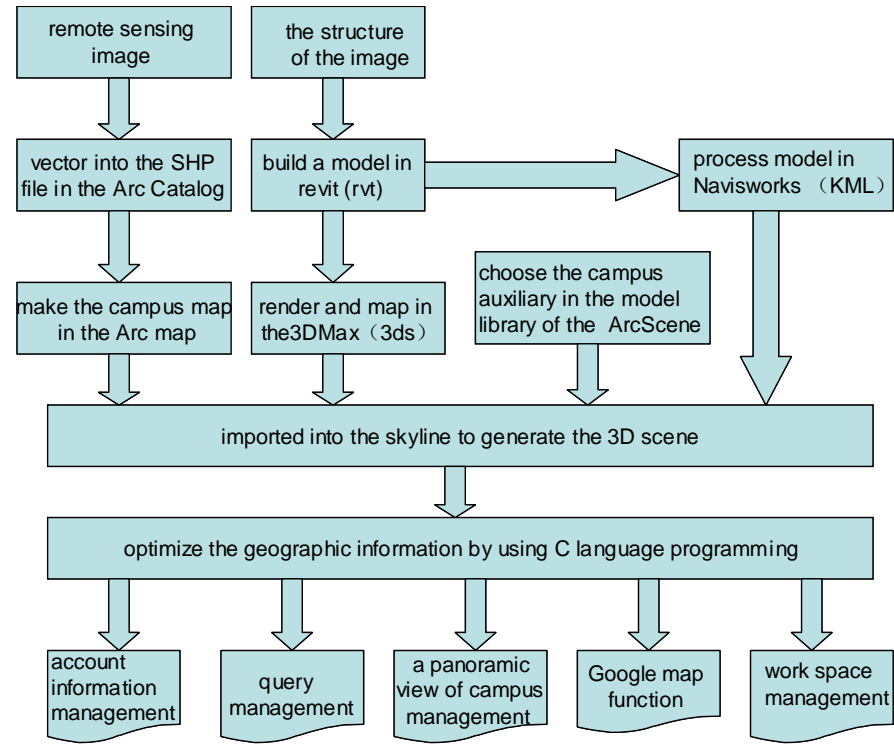

Fig. 2. The technology roadmap.

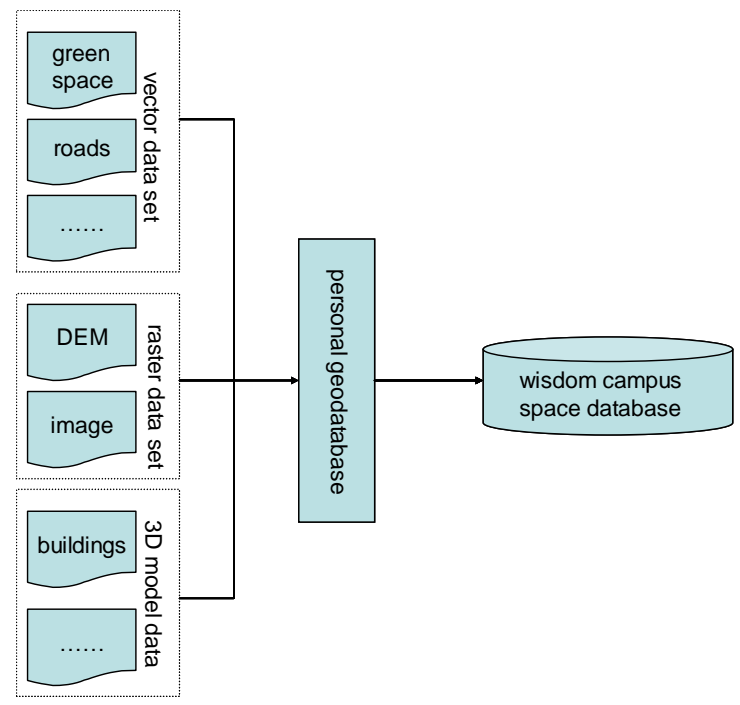

Fig. 3. Spatial database content.

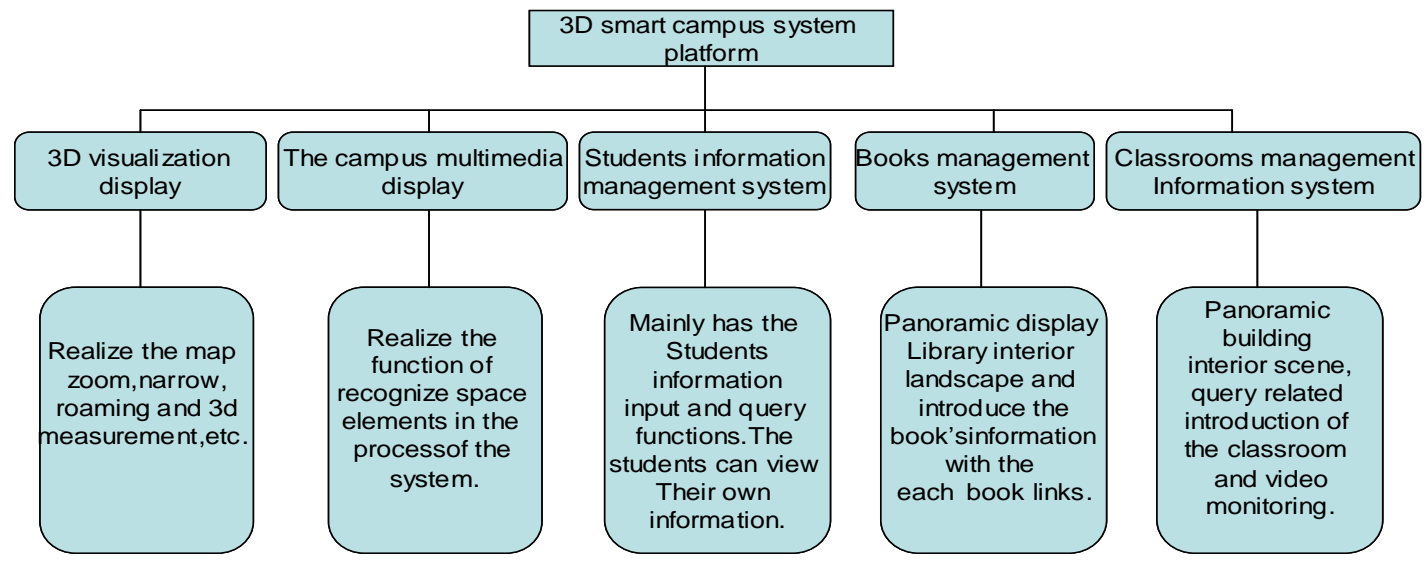

Fig. 4. The design of system functions.

The database includes vector data, grid data and model data. This paper uses the ArcGIS platform to store 
the 3D spatial data and attribute data, and to create three-dimensional campus space database as shown in Fig. 3. In the database, vector data includes roads, houses, greening, playground, etc. Raster data includes DEM data and high resolution remote sensing image data. 3D model data includes teaching buildings, street lamps, etc.

\subsection{Function Design}

The system design structure as shown in Fig. 4 is mainly divided into five function modules. It consists of 3D campus display, multimedia display, student management, books management and classrooms information management. With the realization of these functions, smart campus can provide a comprehensive intelligent perception information service platform to promote the wisdom of teaching, scientific research, management and life.

\section{Realization of Smart Campus}

\subsection{Based on the Revit to Build 3D Models of the Campus}

Revit is a kind of application software, and the biggest problem is that 3DGIS and BIM technology have no uniform standards and formats. Similarly, the Revit and Skyline also exist such problems [16]. So in the design, as shown in Fig. 5 and Fig. 6, we could use lumion bridge to translate BIM model into 3Dmax model to realize the unified data standards. This article takes Shenyang Jianzhu University library as an example to establish model database.

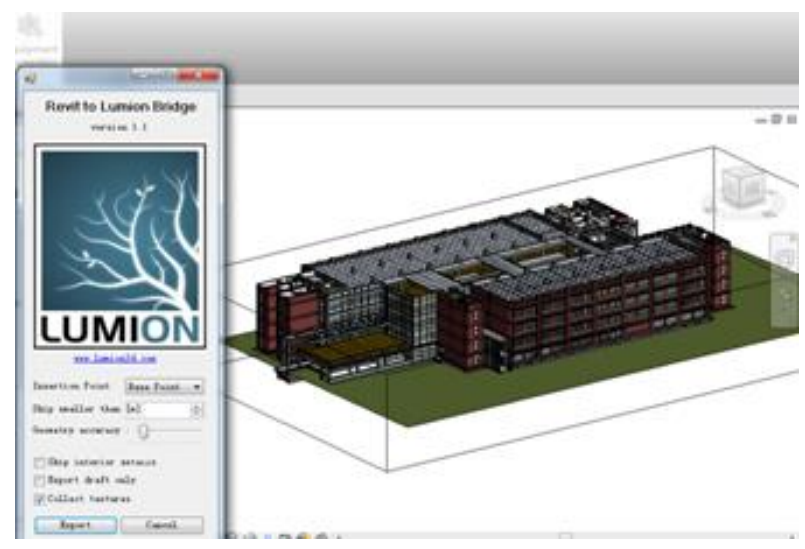

Fig. 5. The library's BIM model in Revit.

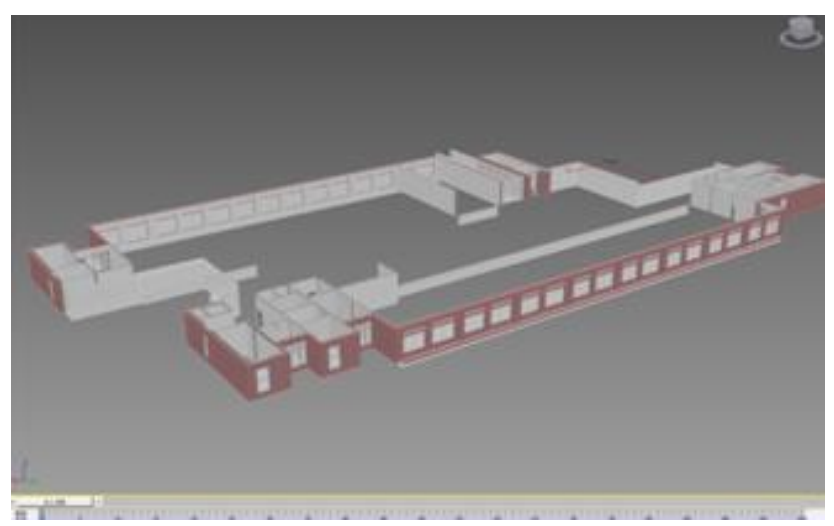

Fig. 6. The windows and doors (3DMax).

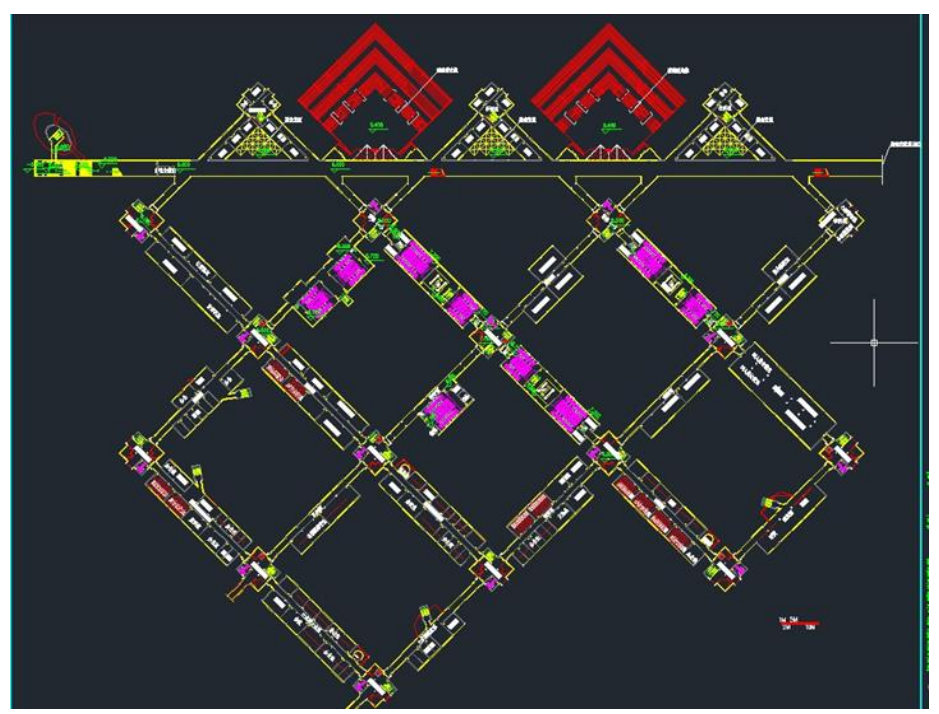

Fig. 7. The plan of the buildings. 
The building information is just a pile of digital records. It needs the 3DMax software to express them. Therefore, this article mainly uses Revit to complete the 3D information model construction. Firstly, the 3D data based on the plan of the building is showed in Fig. 7. And then Revit software transforms the model into DAE and 3ds formats. Finally, it imports the model into the skyline to realize the real actualization. Without changing the model accuracy, it enhances the visualization effects and also represents the fusion of structures and environment.

\subsection{Based on Skyline to Realize the Smart Campus}

Smart campus system integrates the position information of GIS, Internet of Things and multimedia data together to realize the mutual linkage. The design implements the following functions:

1) The location function can quickly locate the classrooms, laboratories, dormitories and office in campus to provide simple and fast method for the teachers and students.

2) Campus information system function can provide the query of the relationship between curriculum and classrooms.

3) Fig. 8 shows that campus camera based on the internet of things function provides relevant situation of campus resources, video monitoring information and the intuitive 3D scene in real time.

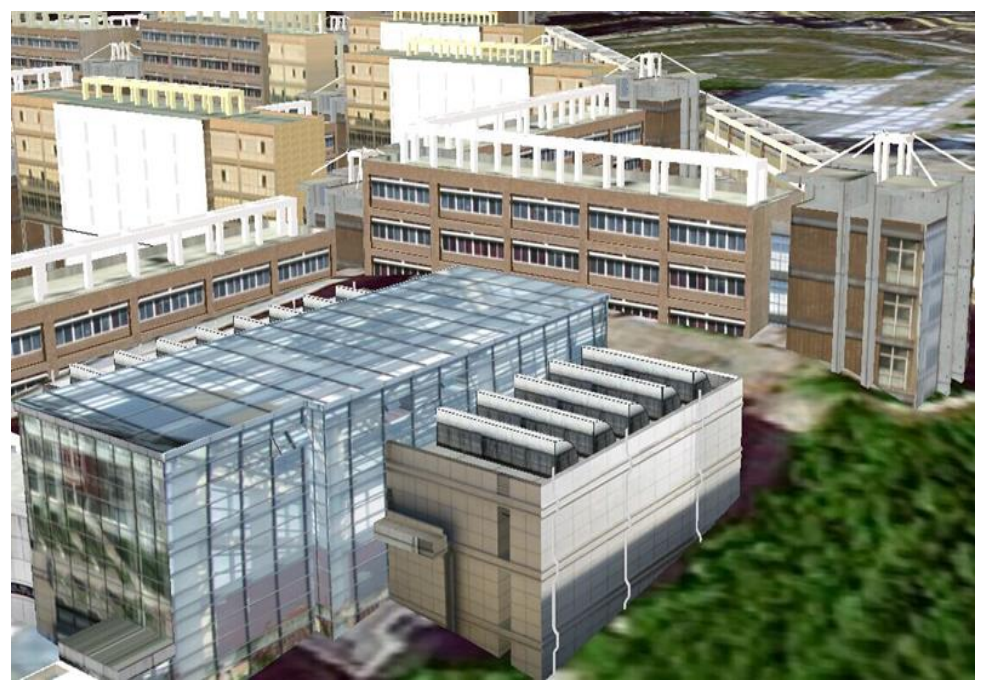

Fig. 8. 3D scene of the campus.

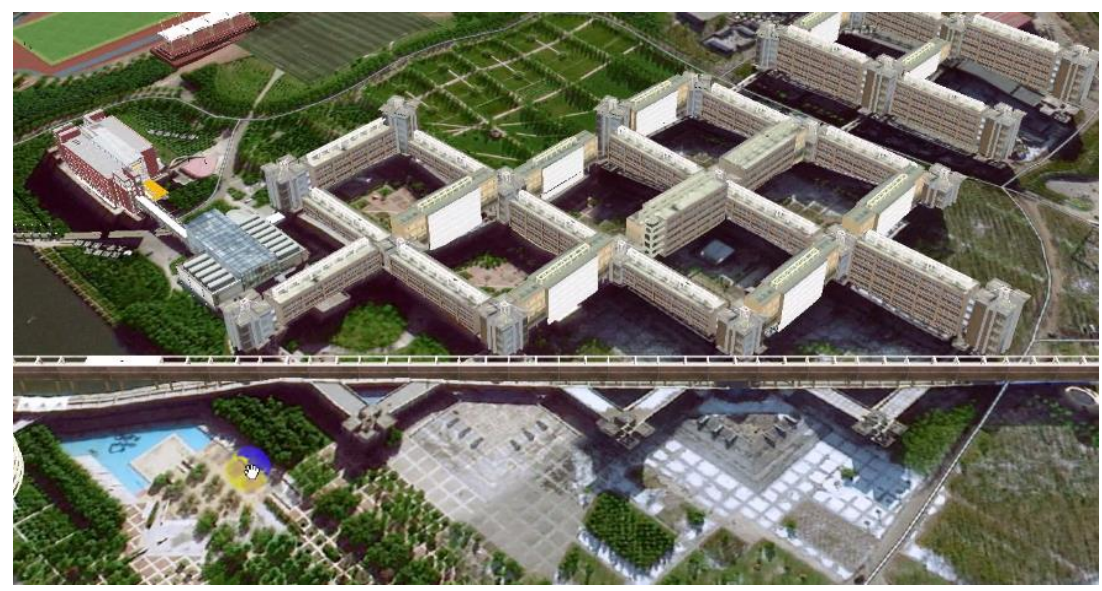

Fig. 9. A panoramic view of the campus.

4) The building construction cost budget function can work out the total cost and each item price.

5) Campus infrastructure management system based on GIS technology can pay attention to the running state of infrastructure and browse the underground pipeline. 
6) Measurement function can measure three-dimensional horizontal distance, vertical distance, space distance and area.

7) Fig. 9 shows a panoramic view of the campus.

\section{Innovation Points}

3DGIS and BIM are new technologies. At the present stage, the combination of the two technologies, not only has important research value, but also has certain practical significance.

First of all, the smart campus advocates the usage of BIM technology and GIS technology. For one thing, the combination of them can make the existent three-dimensional model greatly used. For another thing, it also can promote the construction analysis, urban planning, and rail transit construction and so on. The paper introduces BIM technology into GIS technology to effectively integrate project and make the GIS system to keep the dynamic monitoring entities of the geographic information, geographic conditions and physical location.

Secondly, this paper attempted to combine Revit software and Skyline software together, which can make up the lack of spatial coordinate information of the Revit model. The combination of the two technologies is more accurate display the three-dimensional entity model and realizes the visualization of the 3D campus, which can meet requirements of the campus macro planning.

\section{Conclusions}

Smart campus system construction is based on geographic information system technology. What's more, it introduces BIM technology into campus information management. This paper puts forward to the smart campus design functions and system construction plan. It is a piece of important guidance to build smart colleges and universities. However, the research and construction are still in their infancy and have many difficulties. So we should strive to improve maturity and reliability of technology, and promote the sustainable development of the smart campus system construction.

\section{Acknowledgment}

The authors would like to acknowledge the support from the Shenyang Jianzhu University of China. This work was supported by program for discipline training in Shenyang Jianzhu University of China (Grant No. XKHY2-78), Liaoning Science Public Welfare Research Fund (Grant No.2014004010), and Liaoning Social Science Planning Fund (Grant No.L14CGL040).

\section{References}

[1] Yu, C. H., \& Wang, Y. W. (2013). The goal of digital campus construction under the background of big data. China Educational Technology, 10, 35-41.

[2] Huang, L., Xie, Z., \& Luo, X. G. (2015). Design and implementation of campus service platform. Science of Surveying and Mapping, 9, 69-73.

[3] Zhang, M. D., \& Zhu, S. Y. (2013). Research on ecological construction of digital campus in colleges and university. Modern Educational Technology, 4, 50-55.

[4] Togboa, S. S. (2012). Integrating the Emona FOTEx interface into the batched iLabs client. Proceedings of 2012 International Conference on Interactive Mobile and Computer Aided Learning (pp. 86-91).

[5] Liu, H. T. (2015). Strategy research on the construction of intelligent campus in colleges and university. China Mangement Informationization, 7, 206-207.

[6] Yang, J. (2015). Discussion on the construction scheme of intelligent campus. Mobile Communication, $19,40-44$. 
[7] Xue, R., Wang, J., \& Chen, L. (2011). Using the IOT to construct ubiquitous learning environment. Proceedings of 2011 Second International Conference on Mechanic Automation And Control Engineering (pp. 7878-7880).

[8] Yang, J. F. (2013). Research on personalized intelligent digital campus construction. Electronic Technology, 10, 17-19.

[9] Wu, Y., \& Yin, G. H. (2015). Some thoughts on the construction of smart campus. Information and Computer(Theory), 13, 167-178.

[10] Yang, T. L., \& Yuan, Y. B. (2015). Study on the design of intelligent project based on GIS technology. Value Engineering, 7, 74-75.

[11] Hong, L., Yang, H. J., \& Yang, K. (2014). Design and implementation of dimensional digital campus based on SketchUp and ArcGIS. Geospatial Information, 1, 84-86.

[12] Zhang, X. K., Xue, Y., \& Peng, Q. (2015). Modeling and implementation of 3D digital campus based on Skyline. Journal of Hunan City University: Natural Science, 1, 74-78.

[13] Zhang, S. G. (2014). Design and implementation of WebGIS based three dimensional intelligent campus. Architecture Beijing, 14, 79-84.

[14] Atif, Y., Bad, Y., \& Mamar, Z. (2010). Towards a new-digital learning Ecosystem based on autonomic Web services. Proceedings of 2010 4th IEEE International Conference on Digital Ecosystems and Technologies (pp. 180-185).

[15] Chin, J., \& Callaghan, V. (2013). Educational living labs: a novel internet-of-things based approach to teaching and research. Proceedings of 2013 9th International Conference on Intelligent Environments (pp. 1-6).

[16] Zhou, W., Cui, B., Wang, B., Shi, Q., \& Yokoi, S. (2012). An exploration of ubiquitous learning in computer fundamental learning scenario. Proceedings of 2012 7th International Conference on Computer Science Education (pp. 1420-1424).
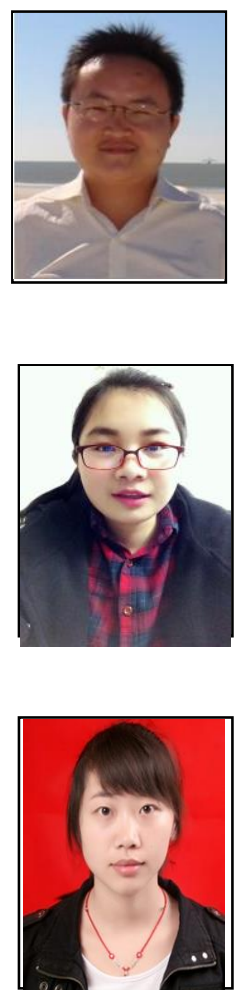

Tianping Bi was born in Henan, China in 1979. He received his Ph.D. degree from Northeastern University. He is working as an associate professor in Shenyang Jianzhu University, China. He won five computer software copyrights. His areas of interest include geographic information system(GIS), and computer software development.

Xuemei Yang was born in Jiangsu, China in 1992. She reveived her bachelor degree of engineering from Huaiyin Institute of Technoligy, China, in June 2015. She is a postgraduate student in Shenyang Jianzhu University, China. Her research interests is urban mangement.

Meili Ren was born in Henan, China in 1988. She received her bachelor degree of management from Nanyang Normal University, China. She is a postgraduate student in Shenyang Jianzhu University, China. Her research interests include design and research of smart campus. 